\title{
Ciencias Sociales y Humanidades
}

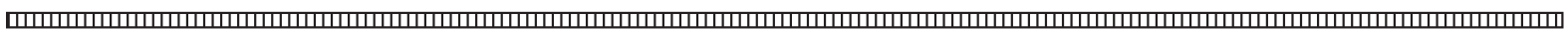

ISSN: 2409-3475 (electrónico) / 2410-6291 (impreso)

Volumen 2 Número 2 julio / diciembre 2015

https://doi.org/10.36829/63CHS.v2i2.128

\section{Editorial / Editorial}



$\mathrm{H}$ ace un año dimos inicio a una especial encomienda, editar Ciencias Sociales y Humanidades, Revista Investigación y Postgrado, un esfuerzo editorial de la Dirección General de Investigación y de la Coordinadora General del Sistema de Estudios de Postgrado, ambas dependencias de la Universidad de San Carlos de Guatemala, un ejercicio que en definitiva ha significado crecimiento.

Los números previos de las revistas como el presente se muestran misceláneos, aunque esta edición tiene un puente en común — con tres excepciones-, los materiales presentados son producidos por académicas, el pulso de una generación de mujeres que con su trabajo realizan acciones críticas en este concierto patriarcal.

Es importante advertir que este número resultan diacrónico en relación a los eventos nacionales que corrieron junto a este segundo semestre del 2015, cuando la Guatemala ciudadana latió como no lo hacia desde hace mucho. Siendo las ciencias sociales el eje de nuestra temática, y la movilidad social de particular interés, estos eventos merecen al menos ser aludidos para que futuros lectores sepan desde estas letras que no escapamos a este despertar. La única consideración más quisiera agregar a este editorial, es la participación de la practicante del ejercicio profesional supervisado de la licenciatura en letras, Nicté Guzmán, quien en su práctica profesional dio muestras de sus habilidades, formación y calidad académica, por lo cual debemos mencionar en este esfuerzo.

Da inicio nuestra sección de artículos, Claudia Dary, antropóloga destacada que aborda el ejercicio de la interculturalidad en un segmento que aunque mayoría es poco atendido, la juventud. En un intere- sante trabajo que titula, "Interculturalidad en lo concreto: tres experiencias desde y para la juventud", nos introduce a este término de características polisémicas, que se hace más complejo si se aplica entre los jóvenes. El trabajo recoge tres experiencias, dos desde lo simbólico-cultural, la estética y la convivencia, la otra como una práctica cotidiana, un universo simbólico por demás imbricado en donde el lector encontrará nuevos aires y ópticas que solo dan este segmento de la población al que podríamos definir como el futuro inmediato.

Continúa un artículo que junto al último de esta sección dan sentido a nuestra portada. Se trata del estudio de Guísela López, "Alaíde Foppa aportes para una educación inclusiva", donde presenta a la poetisa en el ambito de la producción del conocimiento, particularmente en la educación superior, destacando sus aportes en la academia, y otros esfuerzos de donde derivaron la cátedra prima, "Estudios de la Mujer", o la revista $F e m$, en su momento el más importante órgano de difusión del feminismo hispanohablante. López suma con este estudio, un aporte más a los diversos enfoques que sobre esta escritora se han ido derivando, sin duda una de las mejores formas de rendir tributo a los una de los nuestras, estudiándola y por nuestra parte difundiéndola.

En seguida, María del Carmen Muñoz Paz atiende a un personaje central de nuestra historia, el sabio Jose Cecilio del Valle, a quien aborda desde sus preocupaciones por la disciplina de la estadista en un esfuerzo destacado que le merece el apelativo de precursor de la disciplina. Teniendo como marco los años de $1820 \mathrm{y}$ 1822, y partiendo de lo externado por del Valle en una serie de artículos escritos para El Amigo de Patria, 
Muñoz Paz construye su propuesta. Se trata de un trabajo en donde la autora logra que las fuentes adquieran nuevamente fuerza. Oportuno estudio si lo vemos a la luz de esta nación, hoy mas que nunca cuestionada por la falta de una renovación autentica de los estadistas que deben regir sobre nuestro futuro.

Luego Magda Aragón Ibarra, historiadora que se ha dedicado a las relaciones geográficas, con un estudio que denomina, "El Estado de Guatemala y el trabajo cartográfico", enmarca las instituciones encargadas desde el siglo XIX en levantar el mapa oficial de la república, con todas las implicaciones que un evento de este tipo tendría desde fijar las políticas de desarrollo, planificar enseñanza, nociones de territorialidad y pertenencia, todo un abanico que atraviesa, digamos, por una identidad geográfica. Desde la diplomacia, al catastro, la certeza jurídica, los recursos humanos y naturales, hacen de este esfuerzo, aquello que Benedic Anderson (2007) denomina imaginar la nación.

Sigue el turno a Frieda Liliana Morales Barco, estudiosa de la literatura infantil y develadora de temas de la Guatemala decimonónica y del siglo XX. Morales Barco pone el foco sobre Marilena López importante promotora de los títeres en Guatemala, un recurso vital para la docencia, un recurso que hoy sigue siendo menospreciado en una Guatemala que sigue reprobando su atención a la niñez. En definitiva el artículo de Frieda Morales resulta una llamada de atención en relación a las herramientas que solemos dejar por un lado, a pesar de su importancia central. Como en otras ocasiones esperamos que este artículo como los otros, llegue a los tomadores de decisiones.

Finaliza la sección de artículos el trabajo ya aludido. Un estudio de Carmen Barrios, académica residente en Canadá que nos presenta, "El viaje de Beatriz — La Sin Ventura - en la mirada feminista de Alaíde Foppa", un análisis del poema épico La Sin Ventura (1955), que la autora enmarca entre el género de los relatos de los viajeros al Nuevo Mundo. Un valioso acercamiento a un personaje central en la historia de la conquista, Beatriz de la Cueva la esposa del sanguinario conquistador Pedro de Alvarado. Hubiésemos querido incluir el poema, múltiples factores no permitieron incluir esta bella edición ilustrada, una deuda que queda con nuestros actores y que esperamos cumplir para una edición futura. Barrios localiza por cierto este poema en Canadá en manos de una amiga cuya madre como Foppa fue desaparecida en la larga noche que nos tocó vivir.
En el apartado de los ensayos a la ya consabida residencia del ensayo ganador se suma el primer lugar del campo de ciencias medicas, una inclusión a solicitud de su autor, y una importante consideración a nuestro ejerció editorial.

De esta cuenta damos inicio con el ensayo: "El estudio de lo moral como parte de lo real. Consideraciones ontológicas y epistemológicas en la investigación de lo moral y sus consecuencias metodológicas", de Manuel González Ávila. Se trata de un interesante acercamiento a los procesos humanos, que van desde lo natural, lo individual y lo social, una mirada central para una sociedad que ha ido descuidando las relaciones y vida en sociedad. Gonzales Ávila presenta un texto que camina desde las facultades mentales a las instintivas y de los supuestos o valoraciones que bien pueden ser personales o enmarcadas por lo doctrinario.

El segundo ensayo, "Sapiencia, reflexión y transformación, caminos de la educación superior", corresponde al concurso del área social-humanística, y fue escrito por Nereida Calderón. Se trata de un trabajo que se reflexiona sobre el proceso de enseñanza aprendizaje, y todo los elementos que entran para hacer funcional este. La autora trabajo con varios profesionales egresados de la USAC con los que busco una reflexión mayor, junto a los pensadores del siglo XX, ya sea desde posicionamientos críticos foráneos o desde construcciones locales.

En la sección de documentos Héctor Concohá pone sobre el tapete una interesante paleografía. Se trata de un documento de las postrimerías del siglo XIX, 1892, en el que Los vecinos de San Juan Sacatepéquez solicitan no se obliguen á sus mujeres e hijas á que vayan á ocuparse en los oficios del molido en el Hospital Militar. Un recorte digamos sobre una problemática de abuso que pareciera ser fundacional, tanto en su forma estructural como en su permanencia. Un círculo donde las mujeres a lo largo de la historia han recibido los peores vejámenes.

En archivo incluimos una colección de fotografías seleccionadas para este número por el fotógrafo y antropólogo Guillermo Vásquez que titula "Mujeres sostenedoras de tradición", un bello portafolio de antropología visual que expone diversos roles de las mujeres en contextos de tradición y en donde uno puede darse cuenta de su rol central para la conservación de las mismas y como ejes en torno al cual se expresa la etnicidad de los pueblos. Dejemos al lector sacar sus propias conclusiones desde su propia apreciación. 
Como es costumbre cerramos con homenajes, el espacio dedicado a los que nos dejan y cuya obra a diferencia de su presencia física quedara por más tiempo con nosotros.

El primero a José León Coloch Garnica, personaje clave hasta el momento de su deseos, en la conservación como pieza viva del drama precolombino del Rabinal Achí. Coloch Garnica fue el Quiché Achí que llevara a esta pieza a su proclama, la hiciera sobrevivir a finales del siglo pasado y la ingresara a esta nueva era. Quien mejor para aquilatar esta perdida que Carlos René García Escobar, autor de varios estudios sobre la danza, entre éstos un acucioso estudio sobre el Rabinal Achí.
El otro homenaje corresponde a una partida inesperada, se trata de un adiós a la Dra. Arla Cinderella Stokes Brackett, joven mujer afrodescendiente que surgió a la escena de las luchas y reinvindicaciones sociales y culturales en esta última década, aunque ella ya venía cargando con esa vocación, que entonces había volcado a favor de la población en múltiples jornadas médicas y en la coordinación de distintas organizaciones de salud que trabajan a favor de las poblaciones desposeídas, entre estas de particular interés por su propia auto identificación los afrodescendientes, quienes hasta inicios de este siglo XXI ingresan al crisol de la la proclamada diversidad étnica en la Guatemala que nació luego de los acuerdos de paz suscritos en 1996. 